University of Montana

ScholarWorks at University of Montana

UM Graduate Student Research Conference (GradCon)

Feb 28th, 5:00 PM - 6:00 PM

\title{
Sacralization of the Fifth Lumbar Vertebra
}

Samantha Hofland

University of Montana, Missoula, samantha.hofland@umontana.edu

Follow this and additional works at: https://scholarworks.umt.edu/gsrc

Let us know how access to this document benefits you.

Hofland, Samantha, "Sacralization of the Fifth Lumbar Vertebra" (2020). UM Graduate Student Research Conference (GradCon). 5.

https://scholarworks.umt.edu/gsrc/2020/posters/5

This Poster Presentation is brought to you for free and open access by ScholarWorks at University of Montana. It has been accepted for inclusion in UM Graduate Student Research Conference (GradCon) by an authorized administrator of ScholarWorks at University of Montana. For more information, please contact scholarworks@mso.umt.edu. 


\section{Sacralization of the Fifth Lumbar Vertebra: A Case Study}

By: Samantha Hofland with credit to Dr. Kirsten Green Mink and Samantha Ramey M.A.

\section{Abstract}

Sacralization of the fifth lumbar vertebra, also known as Lumbosacral transitional vertebra (LSTV) (Jancuska et al, 2015), is a common congenital pathology that may affect up to $30 \%$ of the population (Alonzo et al, 2018). This condition is characterized by the enlargement, psuedo-articulation or fusion of one or both transverse processes of the fifth lumbar vertebrae to the sacrum.

FSD 19- 232 arrived at the University of Montana Forensic Anthropology laboratory and was assigned by Dr. Kirsten Green Mink to Samantha Ramey and Samantha Hofland for forensic anthropological analysis. This case present unilateral stage 2 sacralization of the fifth lumbar vertebra to the sacral alae on the individual's right side.

Lumbosacral transitional vertebra is a common anatomical variation, but it can lead to other pathological conditions including spinal disc herniation, cervical ribs and Bertolotti's syndrome (Shiksha, 2015). Based on the level of sacralization found on FSD 19-232, it is possible that this individual suffered from Bertolotti's syndrome.

\section{LumboSacral Transitional Vertebra}

Lumbosacral transitional vertebra are common and may occur in as much as $30 \%$ of the population (Alonzo, 2018). This pathology could result in lower backpain in individuals especially when it occurs unilaterally. This pathology is often associated with mutation in the HOX10/HOX11 genes and often runs in families (Jancuska et al, 2015). This congenital pathology is associated more with males than in females (Alonzo, 2018).

There are four stages of LSTV:

stage $I$ is categorized by elongation of the transverse process.

stage II is characterized by a diarthrodial joint where the transverse process articulates with the sacrum but they are not fused.

stage III is when fusion occurs between the transverse process and the

sacrum.

stage IV occurs when one side is stage II and the other is stage III (Castellvi et al, 1984;Jancuska et al, 2015).

There has been controversy about whether stage I actually constitutes sacralization or if the vertebra needs to articulate with the sacrum (Bustos, 1926). Bilateral stage III has often been associated with indigenous peoples from South America (Bustos, 1926).
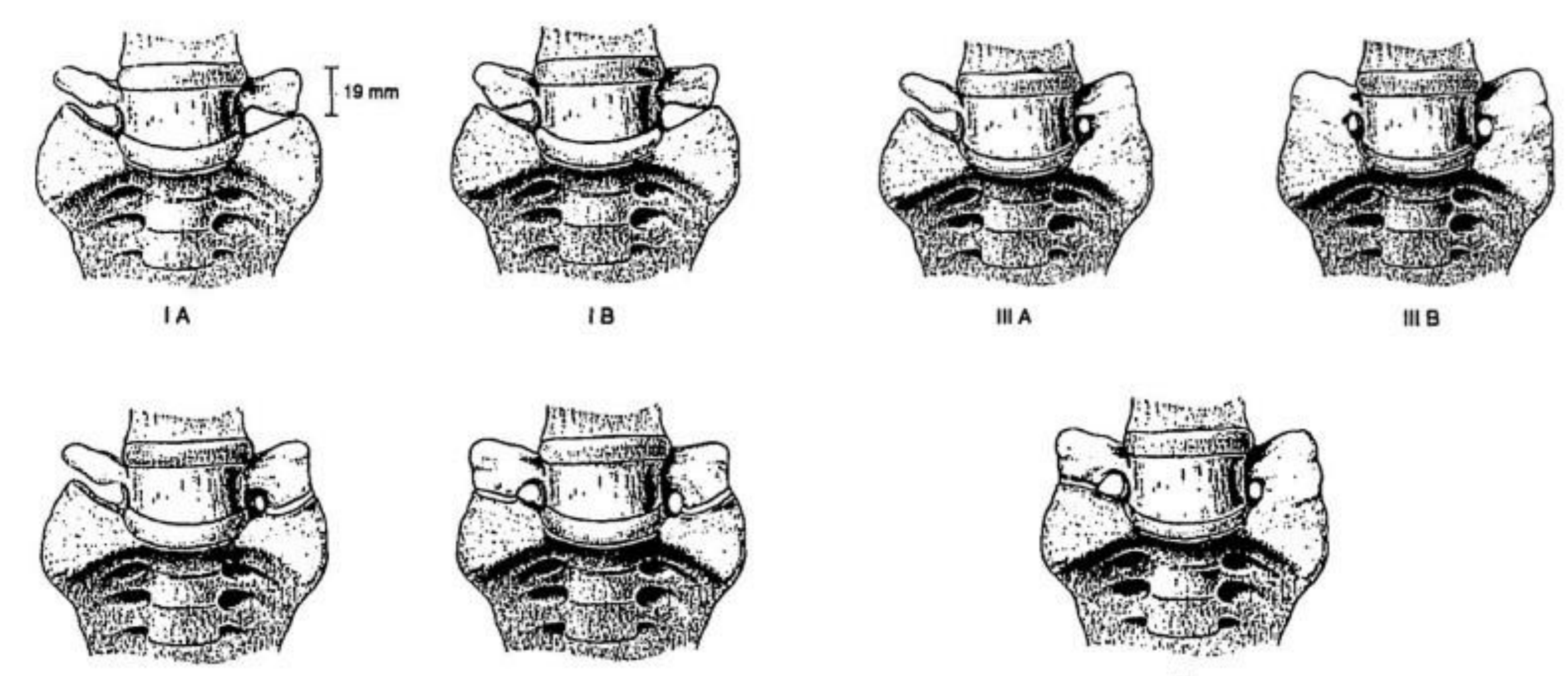

\section{Bertolotti's Syndrome}

Bertolotti's syndrome is a type of LSTV in which the fifth lumbar vertebra articulates with or fuses to the first sacral element (Malham et al, 2013). This articulates with or fuses to the first sacral element (Malham et al, 2013). This motion (Malham et al, 2013). Bedo-ath's syndrome was fist describe in 1917. Ther is (Malham et al, 2013). Bertoloti's syndrome was firt describe in 1917. There is some controversy surrounding Bentoloti's syndrome, some studies have shown that this spinal anomaly is not associated wh lower back pain and others show that Ber. The Walz, 2010). The pain associated with Bertolotti's syndrome maybe caused not only by psuedo-arthritis but also by pressure on the nerve(s), ligament strain, and of the soft tissue due to the point of sacralization (Shiksha, 2015).

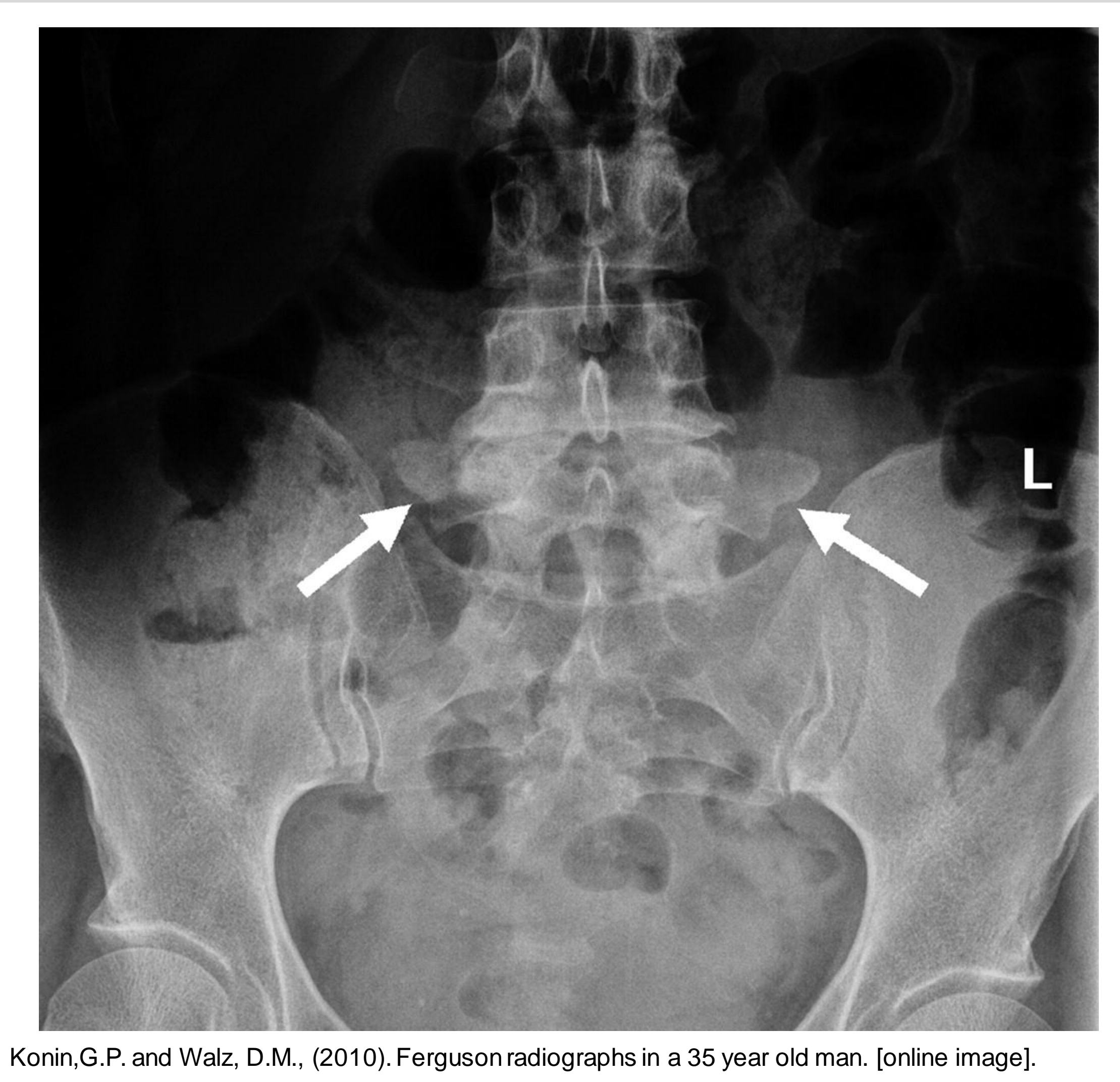

Broader Impacts

It is important to research lumbosacral transitional vertebra for many reasons. In the medical field this may give new insight to lower back pain especially in young individuals and treatments could be developed (Manmohan et al, 2015). In forensic and biological anthropology this pathology could be significant in the identification procedure carried out by forensic anthropologist for significant in the identicalion procedure carried out by forensic anthropologist for law enforcement. This pathology could be used as a secondary characteristic be used with other method to confirm the identity of the individual when the descendent has medical records indicating this condition.

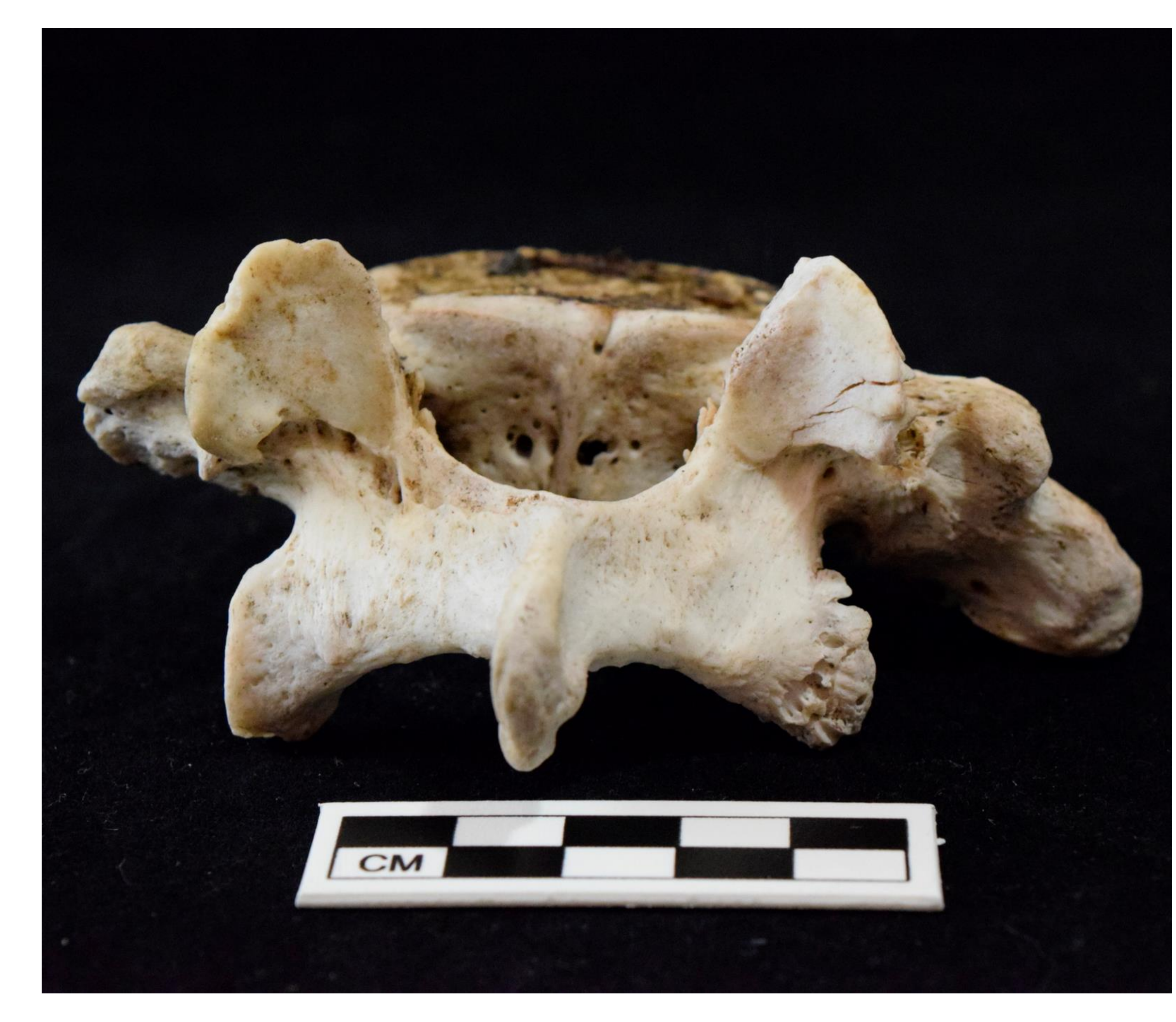

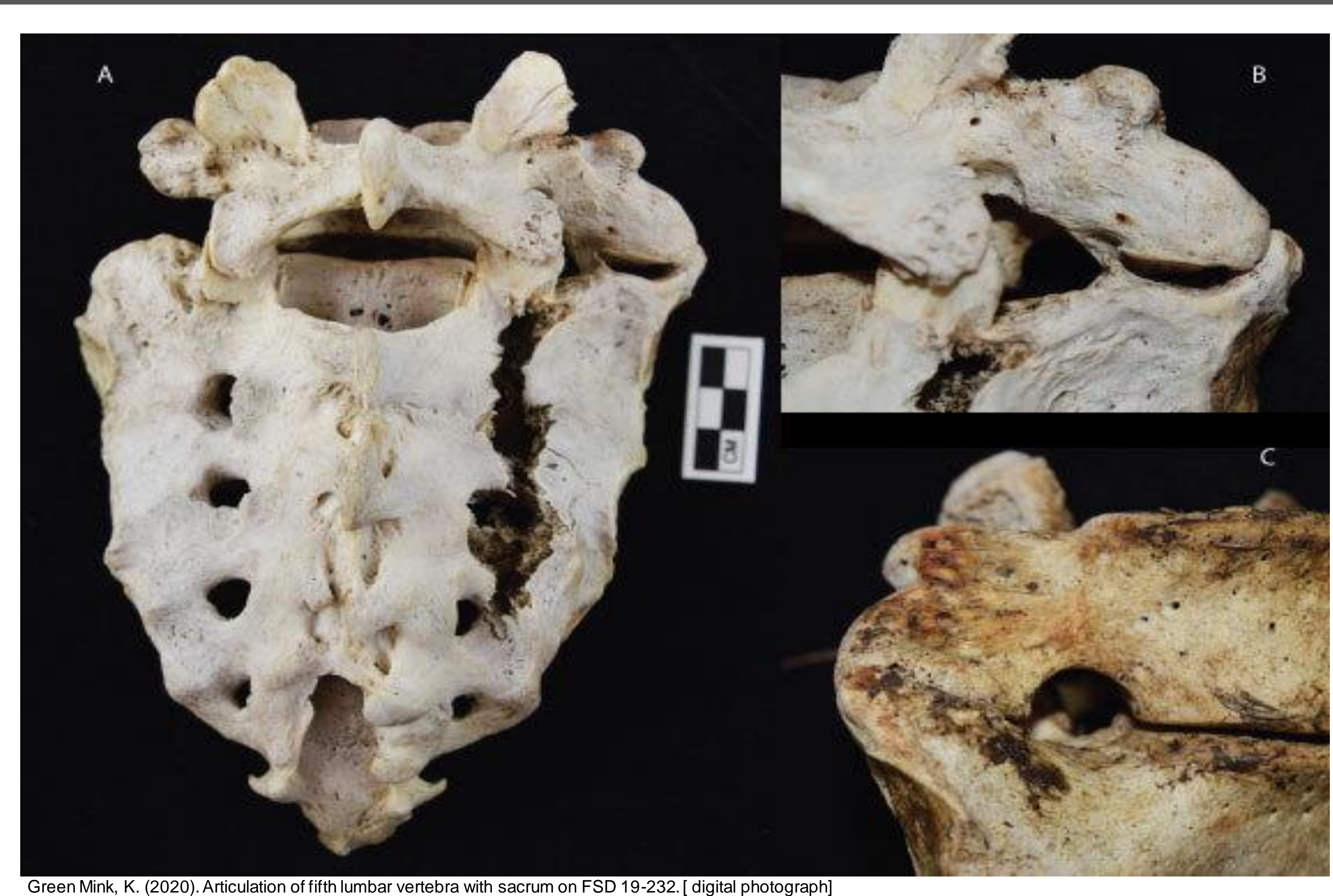

Conclusion

Bertolotti's syndrome is a painful condition caused by and lumbosacral transitional vertebra. This condition has varying degrees and can be generally classified into four categories. FSD $19-232$ presented with a unilateral stage syndrome. This individual had pathologies consistent with osteoarthritis. These signs were more obvious in the spine and on the right side of the axial skeleton. Along with the signs of osteoarthritis, it is likely that this individual may have had movement limitation because of this pathology. This suggest that there was likely pain associated with the sacralization of this individuals fifth lumbar

\section{Acknowledgements}

I would like to thank the Montana State Crime Lab for allowing us access to FSD 19-232. I would also like to show my appreciation to Dr. Kirsten Green Mink for assigning this case to me as well as supervising this case. I would also Mink for assigning this case to me as well as supervising this case. I would also
like to give credit Samantha Ramey for leading this case as well helping identify the pathology discussed in this presentation.

\section{Works Cited}

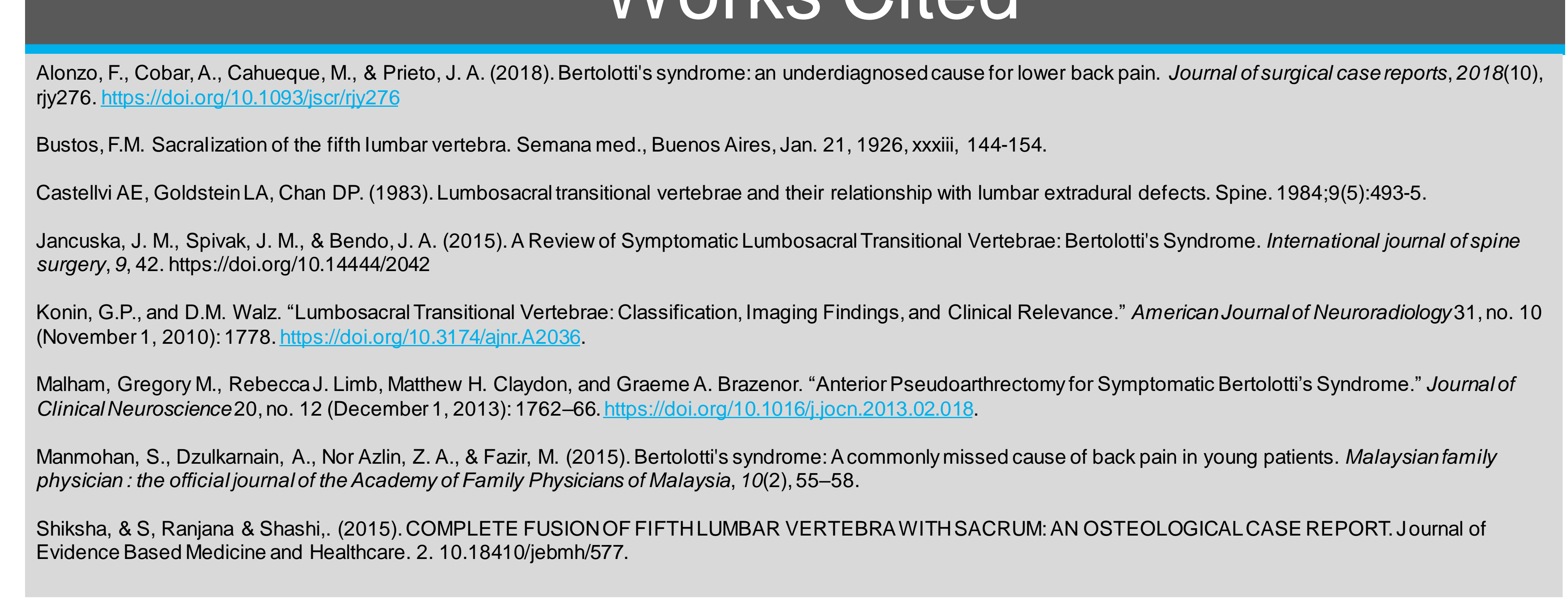

